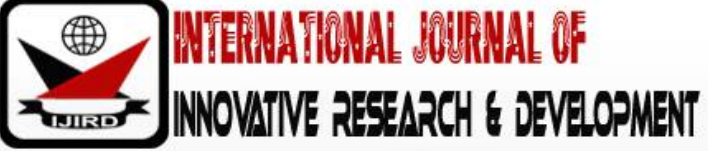

ISSN 2278 - 0211 (Online)

\section{Geriatric Anxiety and Cognitive Functioning among Flders: The Case of Two Selected Care Centers in Addis Ababa, Ethiopia}

\section{Ephrem Habte Shikuro \\ Assistant Professor, College of Education and Behavioral Studies, Jigjiga University, Ethiopia}

\begin{abstract}
:
Background: Old age is accompanied by different forms of physical and psychological problems. This study aimed to investigate cognitive functioning among elders with symptoms of depression.

Methods: This study employed a cross-sectional descriptive survey. In this study, 116 participants were purposefully selected out of 148 elders from two institutionalized care centers in Addis Ababa with inclusive criteria. The instruments of data collection were GAI-20 and MMSE. Mean, Standard deviation, t-test, ANOVA, and Pearson correlation coefficient were used as methods of data analysis.

Results: This study showed that the elders had high rate of anxiety (63.8\%). In addition, $87.1 \%$ of elders had declined cognitive functioning. Similarly, the study indicated that there was statistically significant inverse relationship between anxiety and cognitive functioning $(r=-0.511, \mathrm{p}<01)$.

Conclusion: The finding revealed that anxiety and cognitive decline were higher among the elders. Females had lower cognitive functioning compared to their male counterparts. An increased age and lower level of literacy were associated with lower cognitive functioning and higher symptoms of anxiety. I suggest that further research is needed to be conducted on non-institutionalized elders.
\end{abstract}

Keywords: Geriatric anxiety, cognitive functioning, elders

\section{Introduction}

Old age is defined in different ways by different groups, societies and countries. Terms such as elderly, older person, and old age are often used interchangeably referring to people who are 60 and above [1,2]. The old age starts in the sixties [1]. However, others contended that the period of old age includes people with the age of 65 and above. So, there is no clear demarcation points concerning the period of old age [3].

United Nation (UN) defines aging in relation to people whose age is 60 years and above [4]. This definition has gained acceptance in the Ethiopian context as it coincides with the country's official retirement age [2]. Hence, in this study, terms elderly and older people are, therefore, used interchangeably referring to all people aged 60 and above. United Nation's Statistical report indicated that 962 million people, $13 \%$ of the global population, were estimated to be 60 and above [4]. In Ethiopia, there were more than 4.2 million elders in 2013[5]. This figure is projected to 5.2 million by the year 2020 [6].

The condition of elders is highly accompanied by various forms of physical and psychological problems compared to other stages of development $[7,8,9]$. Similarly, depression and anxiety are among the commonly reported psychological problems among the elders [10]. Accordingly, this paper aimed at investigating the cognitive functioning among elders with symptoms of geriatric Anxiety.

According to the WHO, more than 264 million people throughout the world suffer from anxiety [11]. Almost one in every four-elderly people, for example, suffers from serious cognitive decline, which is a major risk factor for later development of dementia [13,14].Researchers have witnessed that, generally Africa, specifically; Ethiopia is characterized by famine, drought, disease, and civil conflicts. These factors substantially decrease coping skills among the elderly [7].

Depression and Anxiety are among the most prevalent form of psychological problems in Ethiopian communities, affecting people of all ages, socioeconomic classes, and educational levels. There were various studies conducted on Geriatric Anxiety and cognitive functioning in different parts of the world. However, in Ethiopia, there are no clearly documented data on this issue. Therefore, this study attempted to fill this gap by studying the prevalence of geriatric Anxiety and cognitive functioning among institutionalized elders in Addis Ababa. In addition, the variables were investigated across different socio-demographic variables.

\section{Methods}

\subsection{Study Design and Area}

The study design was a cross-sectional descriptive survey. The study tried to investigate elder's cognitive functioning with symptoms of anxiety. The elders were aged 60 and above. They were chosen from two institutionalized 
care centers in Addis Ababa, Ethiopia, namely; Kaliti Institutional Care Center for the Elderly (KICCE) and Kibre Aregawuyan Migbare Senay Direjit (KAMSD).

\subsection{Inclusion and Exclusion Criteria}

The elders were selected based on the following inclusion/ exclusion criteria. The inclusion criteria included elders who were: a) aged of 60 and above, b) willing and able to give their consent, c) had no major other psychiatric disorder, d) had no significant sensory and/ or language impairments and e) did not participate in the pilot study. On the other hand, participants those who did not met the inclusion criteria were automatically excluded.

\subsection{Sampling and Participants}

The participants of the study were selected by using purposive sampling technique. Out of total of 148 elders, 116 elders who fulfilled the inclusion criteria were selected. Sixty-eight of them (58.62\%) were male and the remaining $48(41.37 \%)$ were female.

\subsection{Instruments of Data Collection}

The instrument of data collection for depression was Geriatric Anxiety Inventory (GAI). The scale is valid and reliable, even across cultures [18]. A pilot test was conducted on 15 participants and the reliability of Cronbach alpha of 0.79 was obtained. The Geriatric Anxiety Inventory (GAI) consists of 20 "Agree/ Disagree" with Possible scores range from 0 to 20. Items are designed to assess typical common anxiety symptoms among older people and has inter item consistency of approximately $\mathrm{r}=0.9$ to identify the optimum GAI-20 cut point to identify patients with any anxiety symptoms, it is found an optimum cut point of $8 / 9$, which correctly classified $78 \%$ of patients with a sensitivity of $73 \%$ and specificity of $80 \%$. According to the GAI-20, higher scores indicate the presence of more anxiety symptoms. In screening part, score 0-7 indicated as normal/ not risky, score 8-14 indicated as mild anxiety symptom and score 15-20 indicted as severe. Besides, GAI has convergent validity with other measures [18].

Similarly, Mini Mental State Examination (MMSE) contains 12 items and it was used to measure cognitive functioning of the elders. Folstein and McHugh reported that for samples of psychiatric patients, at least, the reliability of the instrument was found to be more than 0.82 [19].

\subsection{Method of Data Analysis}

Quantitative data analysis was used by using SPSS.21. In order to assess prevalence of Anxiety and cognitive functioning, and to investigate the relationship between anxiety and cognitive functioning, descriptive statistics (mean, standard deviation, Pearson correlation and frequency distribution) were used. In addition, inferential statistics (t-test and one-way ANOVA) were used to measure mean differences of anxiety and cognitive functioning across demographic variables.

\section{Results}

\begin{tabular}{|c|c|c|c|}
\hline Socio Demographic Variables & Classifications & Frequency & Percent \\
\hline & $60-74$ & 52 & 44.8 \\
\hline Age & $75-84$ & 31 & 26.7 \\
\hline & 85 And Above & 33 & 28.4 \\
\hline & Total & 116 & 100 \\
\hline & Male & 68 & 58.6 \\
\hline Gender & Female & 48 & 41.4 \\
\hline & Total & 116 & 100 \\
\hline Educational Background & Illiterates & 61 & 52.6 \\
\cline { 2 - 4 } & Primary & 45 & 38.8 \\
\hline & High School & 10 & 8.6 \\
\hline & Total & 116 & 100 \\
\hline
\end{tabular}

Table 1: Socio-Demographic Background of Participants

As we can see from table 1, majority of the participants 68 (58.6\%), were male whereas $48(41.4 \%)$ of them were females. In terms of age, nearly half of the elders (44.8\%) were between $60-74$ years of age and the remaining portion is occupied by elders above 75 years. Besides, more than half of the participants who accounted for $52.6 \%$ (61) were illiterates. 


\begin{tabular}{|c|c|c|c|}
\hline Variables & Levels & Frequency & Percent \\
\hline Anxiety & Normal & 42 & 36.2 \\
\cline { 2 - 4 } Symptoms & Mild & 58 & 50.0 \\
\cline { 2 - 4 } & Sever & 16 & 13.8 \\
\cline { 2 - 4 } & Total & 116 & 100 \\
\hline Cognitive & Normal & 15 & 12.9 \\
Functioning & Mildly declined & 38 & 32.8 \\
\cline { 2 - 4 } & Moderately declined & 53 & 45.7 \\
\cline { 2 - 4 } & Severely declined & 10 & 8.6 \\
\cline { 2 - 4 } & Total & 116 & 100 \\
\hline
\end{tabular}

Table 2: The Prevalence of Anxiety and Declined Cognitive Functioning

Table 2 shows that half of the elders $58(50.0 \%)$ had mild anxiety symptoms and $16(13.8 \%)$ of the elders had severe anxiety symptoms. The remaining 42 (36.2\%) of elders were normal in terms of anxiety symptoms.

Concerning level of cognitive functioning, nearly half of the elders 53(45.7\%) had moderate level of declined cognitive functioning followed by elders having mild declined functioning 38(32.8\%). In contrast, $8.6 \%$ of the elders had severe declined cognitive functioning.

\begin{tabular}{|c|c|c|c|}
\hline Symptoms & Total & Percent & Mean Score of MMSE \\
\hline Positive(mild/ severe) & 74 & 63.79 & 14.06 \\
\hline Negative (normal/not risky) & 42 & 36.20 & 21.03 \\
\hline Total & 116 & 100 & \\
\hline Table 3: The Mean Scores of Cognitive Functioning among Elders with \\
Positive and Negative Symptoms of Anxiety
\end{tabular}

The above table (3) shows that elders with mild and severe form of anxiety had 14.06 mean score of MMSE and elders without anxiety symptoms mean score was 21.03. This implies that those elders who were positive in anxiety had manifested moderate decline in cognitive functioning than those elders having no (less) symptoms of anxiety.

\begin{tabular}{|c|c|}
\hline Variables & Anxiety \\
\hline Anxiety & 1 \\
\hline Cognitive Functioning & $-.511^{* *}$ \\
\hline
\end{tabular}

Table 4: Correlations between GAI-20 and MMSE

$* * \mathrm{P}<.01$ Level (2-Tailed)

Pearson correlation coefficient was calculated and the result showed that there is a significant moderately negative $(r=-.511)$ relationship between anxiety and cognitive functioning. It implies that, when anxiety increases, cognitive functioning decreases moderately.

\begin{tabular}{|c|c|c|c|c|c|c|c|}
\hline Variable & Groups & $\mathbf{N}$ & $\mathbf{M}$ & SD & Df & T & Sig. \\
\hline Gender & Male & 68 & 9.10 & 4.038 & 114 & -.519 & .605 \\
\hline & Female & 48 & 9.52 & 4.580 & & & \\
\hline
\end{tabular}

Table 5: Anxiety and Gender

$\mathrm{M}=$ Mean SD = Standard Deviation $\mathrm{DF}=$ Degree of Freedom

At-test was calculated to know if there was difference in Anxiety between male and female elders. The result showed that there was no statistically significant difference in anxiety between male and female elders, $\mathrm{t}=-.519, \mathrm{df}=114$, $\mathrm{p}>05$.

\begin{tabular}{|c|c|c|c|c|c|c|c|}
\hline Variables & Groups & $\mathbf{N}$ & $\mathbf{M}$ & SD & Df & t & Sig. \\
\hline Gender & Male & 68 & 19.57 & 5.516 & 114 & $2.848^{*}$ & .005 \\
\hline & Female & 48 & 16.60 & 5.550 & & & \\
\hline
\end{tabular}

Table 6: Gender and Cognitive Functioning

$* \mathrm{P}<05 \mathrm{M}=$ Mean $\mathrm{SD}=$ Standard Deviation $\mathrm{DF}=$ Degree Of Freedom

To check gender difference in cognitive functioning among elders, a t-test was computed. The result of data analysis indicated that there was a statistically significant difference between male and female elders $t=2.848 *, d f=114$, $\mathrm{p} * \mathrm{P}<05$. This implies that, relatively male elders have higher cognitive functioning than female elders. 


\begin{tabular}{|c|c|c|c|c|c|c|}
\hline Variables & & SS & Df & MS & F & Sig. \\
\hline Age & Between Groups & 172.995 & 2 & 86.497 & $5.117^{*}$ & .00 \\
\hline & Within Groups & 1910.178 & 113 & 16.904 & & \\
\hline & Total & 2083.172 & 115 & & & \\
\hline Educational & Between Groups & 393.511 & 2 & 196.756 & $13.158^{*}$ & .00 \\
Background & Within Groups & 1689.661 & 113 & 14.953 & & \\
\hline & Total & 2083.172 & 115 & & & \\
\hline
\end{tabular}

Table 7: Comparison of Anxiety Symptoms across Age and Education

$* \mathrm{P}<05 \quad \mathrm{SS}=$ Sum Squares; MS = Mean Square; DF = Degree of Freedom

The statistical analysis disclosed that there is significant difference $(\mathrm{F}(2,113)=5.117, \mathrm{P}<05)$ among elderly across age on their anxiety symptom.

The post hoc result also showed that, elderly aged $60-74(\mathrm{M}=8.00, \mathrm{SD}=4.537)$ were significantly different from those aged 85 and above ( $M=10.85, S D=3.528)$, but the rest did not differ significantly. Besides, Elderly aged 85 and above were found to be more anxious than the rest.

Similarly, as indicated in the above table, there is significant difference $(F(2,113)=13.158, P<05)$ in anxiety symptom among those elders who are illiterate, primary and high school. Besides the descriptive statistics also revealed that, elders who were illiterate have the highest mean score with more deviation from the mean $(\mathrm{M}=11.02, \mathrm{SD}=4.181)$ primary school $(\mathrm{M}=7.22, \mathrm{SD}=3.240)$ and high school $(\mathrm{M}=7.90, \mathrm{SD}=4.458)$. Based on the post hoc result, elderly who were illiterates ( $M=11.02, S D=4.181)$ were significantly different from elders with primary school $(M=7.22, S D=3.240)$ with the mean difference of 3.794. But the rest did not show significant difference. The result revealed that, elderly who were illiterates were more anxious than the rest.

\begin{tabular}{|c|c|c|c|c|c|c|}
\hline Variables & & SS & Df & MS & F & Sig. \\
\hline Age & Between Groups & 399.295 & 2 & 199.648 & $6.765^{*}$ & .002 \\
\hline & Within Groups & 3334.912 & 113 & 29.512 & & \\
\hline & Total & 3734.207 & 115 & & & \\
\hline Educational & Between Groups & 1041.297 & 2113 & 520.648 & $21.847^{*}$ & .000 \\
Background & Within Groups & 2692.910 & & 23.831 & & \\
\hline & Total & 3734.207 & 115 & & & \\
\hline
\end{tabular}

Table 8: Comparison of Cognitive Functioning Across Age and Education

$* \mathrm{P}<05 \quad$ SS =Sum Squares; MS = Mean Square; DF = Degree Of Freedom

The above table shows that, there is statistically significant difference in cognitive functioning among the elders in terms of age and educational background Accordingly, the above table revealed that there is significant difference among elders in cognitive functioning across all age groups, $\mathrm{F}(2,113)=6.765, \mathrm{P}<05$. A post hoc analysis displayed that cognitive functioning of elders aged $60-74(\mathrm{M}=20.38, \mathrm{SD}=5.424)$ significantly differed from those aged $75-84(\mathrm{M}=17.03, \mathrm{SD}=6.074)$ and those aged 85 and above $(\mathrm{M}=16.36, \mathrm{SD}=4.769)$. But those aged 75-84 did not differ significantly from other groups. It was also indicated that elderly aged 60-74 were had higher cognitive functioning than the rest.

As we can see from the above table, there is statistically significant difference in cognitive functioning among all levels of education, $\mathrm{F}(2,113)=21.847, \mathrm{P}<05)$. This implies that elders who were illiterate relatively had more declined cognitive functioning than the other groups. Moreover, elders who were illiterate $(M=15.64, S D=4.719)$ had significant difference from the elderly who were at primary school $(\mathrm{M}=24.20, \mathrm{SD}=2.821)$. Accordingly, the result indicated that, elderly who were at high school level education had higher cognitive functioning compared to the rest.

\section{Discussion}

According to the WHO, more than264 million people throughout the world suffer from anxiety [11]. A study conducted in Andhra Pradesh, the prevalence of anxiety among institutionalized elders was 94.6 \%[15]. Similarly, another finding indicate that the prevalence of anxiety among elders was 5\% [16]. besides anxiety prevalence among elders aged 60 and above was 6.4\%[17]. In comparison with other study, this study revealed that the prevalence of anxiety among institutionalized elders was higher, which counted 63.8\%. Accordingly, I suggest research to be conducted among none institutionalized elders.

Elderly people face many challenges associated with physical and mental deterioration. Evidence suggests that aging is associated with a decline in the ability to perform several cognitive tasks [20]. The finding of this study has been found consistent with other studies in that, anxiety was related to reduced cognitive functioning [21]. Furthermore, according to [22], the subjects with anxiety differed from those without anxiety in being, having more cognitive dysfunction, being more disabled in activities of daily living, feeling lonelier, and being more dissatisfied with life. Moreover, the finding of this study has also shown consistency with the findings of [22].Sample of elderly aged 60 and above showed moderate cognitive decline (based on SMMSE) and most reported with minor depression and anxiety symptom. Cognitive decline in elderly is characterized by impairments in daily activities including memory, decisionmaking ability, planning, organization and mental flexibility [23].One out of four-elderssuffer from serious cognitive decline, which in turn, may result in dementia $[13,14]$. However, results from this study indicated that most of the elders $(87.1 \%)$ had declined cognitive functioning. This is similar with the findings of Bierman and colleagues who found 
depression and anxiety symptom in about 3\% of the subjects with moderate cognitive decline, whereas anxiety was particularly common in subjects with poor cognition [24]. Recently a study [25] has investigated the hypothesis that depressive and anxious symptoms are significantly associated with cognitive functioning in elderly. Their study revealed that there is significant association between depressive and anxious symptoms and decline in cognitive performance among elderly. Similarly Results indicated that although both cognitive functioning and anxious symptoms were within normal limits in their study, anxious symptoms showed a significant, inverse relationship with global cognitive function $(r=-0.400, p=.005)[26]$. This study has also revealed that that there is a significant moderately negative $(r=-.511, p<.01)$ relationship between anxiety and cognitive functioning.

In this study it was identified that there was statistically significant difference $(F(2,113)=5.117, P<05)$ among elderly of age 6074, 75-84 and 85 and above on their anxiety symptoms and Elderly aged 84 and above were found to be most anxious than the rest. Accordingly, the study revealed, there was also statistically significant difference $(\mathrm{F}(2,113)=$ $13.158, \mathrm{P}<05$ ) in anxiety symptom among those elderly who were illiterate, primary and high school. This study showed illiterates were found to be most anxious than the rest. Similarly [27] had also indicated that, there was significant difference in education age in manifestation of anxiety symptom among elderly.

Old age is not only associated to anxiety symptoms but also associated with cognitive decline [28]. This study showed that about half $(45.7 \%)$ of the elders had moderate cognitive decline and $8.6 \%$ of them had sever cognitive decline. Consistently, a study reported that the level of cognitive decline was $31 \%$ among elderly patients in India [29]. Moreover, this study tried to see if there were differences in cognitive functioning across selected socio-demographic variables. In terms of age, consistent with this study, different studies reported that cognitive decline increase as aging increases [29]. Besides, the study indicated that male elders had relatively higher cognitive function compared to their female counterparts. Other studies confirmed the same result [29]. Our study detected that illiterate elders had lower cognitive performance compared to others. In addition, other similar studies indicated that elders more educated elders had less cognitive impairment [29, 30, 31, 32].However, other studies suggested that cognitive functioning is related with educational attainment [33, 34].Likewise, cognitive performance is related to gender. Most studies reported that male elders had better cognitive functioning compared to females [31,35, 36]. Consistently, the present study confirmed this difference.

\section{Conclusion}

The study found that anxiety and cognitive declining was higher among elders in two selected institutionalized care centers in Addis Ababa, Ethiopia. In addition, females scored lower in cognitive functioning compared to males. The study also indicated that increased age and illiteracy were associated with lower cognitive functioning and higher-level anxiety. This implies that elderly programs should consider social support system.

\section{Conflicting Interest}

The author declares that there are no financial and non-financial competing interests.

\section{Acknowledgement}

The author would like to thank the study participants for their genuine responses. In addition, our deepest gratitude goes to program managers of KAMSD and KICCE. Finally, I thank Tefera Tekle, Betregiorgis Gebre and other data collection team for their kind collaboration.

\section{References}

i. Santrock, JW (2006). Life Span Development. (10thed). New York, NY: McGraw-Hill Company.

ii. MOLSA [Ministry of Labor and Social Affairs, Ethiopia] (2006). National Plan of Action for the Elderly. MoLSA, Addis Abeba, Ethiopia.

iii. Riker AP \& Brisbane HI. 1997. Married and Single Life (6 $6^{\text {thed }}$ ). New York, NY: Mcgraw-Hill Company.

iv. UN (2016). Ageing. [online] Available at: http:// www.un.org/ en/ sections/ issues-depth/ageing/ [Accessed 22 Mar. 2018].

v. CSA (Central Statistical Agency, Ethiopia). (2014). Statistical report on the 2013 national labour force survey. Addis Ababa, Ethiopia: CSA.

vi. CSA (Central Statistical Agency, Ethiopia). (2007). National Population and Housing Census in Ethiopia. Addis Ababa, Ethiopia: CSA.

vii. Health and Place Initiative (HAPI) (2014). Physiology and psychology of aging, health, and place. Available online at: http:/ / research.gsd.harvard.edu/ hapi/ files/ 2014/ 10/ HAPI ReserachBrief-Aging-PhyPsy-102814-FINAL.pdf [Accessed 22 Mar. 2018].

viii. Beard JR, Officer, AM \& Cassels, AK (2016). The world report on ageing and health. Gerontologist, 2016, 56(S2), S163-S166. doi:10.1093/ geront/ gnw037

ix. WHO (2011). Global health and aging. Available online at: http:/ / www.who.int/ entity/ageing/ publications/global_health.pdf?ua=1 [Accessed March 22, 2018].

x. Skoog, I (2011). Psychiatric disorders in the elderly. The Canadian Journal of Psychiatry, 56)7), 387-397.

xi. 11. WHO. (2011). Annual inform of disability. Retrieved from Http://www.who.Int/Disabilities/ World Report/ 2011/ Es/ Mindex.Html on December, 8, 2013

xii. WHO. 2017. Depression and other common mental disorders: Global health estimates. Geneva, Switzerland: Author. 
xiii. 13.Unverzagt F, Gao S, Baiyewu O, Ogunniyi A, Gureje O, Perkins A, Emsley C, Dickens J, Evans R, Musick B, Hall K, Hui S. \& Hendrie H (2001). Prevalence of cognitive impairment: Data from the Indianapolis Study of Health and Aging. Neurology, 57(9), pp.1655-1662.

xiv. 14. Park, H., Connell, J, \& Thomson, R. (2003). A systematic review of cognitive decline in the general elderly. International Journal of Geriatric Psychiatry, 18, 1121- 1134.

xv. 15. Kumar P, Udayar S, Arun S (2016). Depression and anxiety among the elderly persons from institutional and noninstitutionalized settings in the field practice area of a tertiary-care institute, Andhra Pradesh: a comparative study.International Journal of Medical Science and Public Health , Vol 5,11

xvi. 16. Seby K, Chaudhury S, Chakraborty R (2011). Prevalence of psychiatric and physical morbidity in an urban geriatric population. Indian J Psychiatry 2011;53(2):121-7.

xvii. 17 Purna SA, Lokesh KK, Pavan Kumar Reddy CM (2012). Psychiatric morbidity in geriatric population in old age homes and community: a comparative study. Indian J Psychol Med 2012;34(1):39-43.

xviii. 18. Pachana, N. A., Byrne, G. B., Siddle, H., Koloski, N., Harley, E., \& Arnold, E. (2007). Development and Validation of the Geriatric Anxiety Inventory. International Psychogeriatrics, 19, 103-114. Retrieved from, http:/ / www.informaworld.com/ CAMHDOI:10.1080/ 13607861003587628, on April, 11, 2013.

xix. 19. Folstein, MF, Folstein, SE, \& McHugh, PR (1975). Mini-mental state: a practical method for grading the cognitive state of patients for the clinician. Journal of Psychiatric Research, 12, 189-198.

xx. 20. Dixon, RA, Backman, B and Nelsson L. (2004). New Frontiers in cognitive aging. Oxford, UK: Oxford University Press.

xxi. 21 Balcom, T. and Geothe, S. (2006). Depression and Anxiety among Elders: Epidemiological Study. Journal of Psychiatric Research, 34, 201-206.

xxii. 22.Gerda, M. Van Der W., Jacobijn G., Margot W., De W., Anton J., De, C., and Roos C. Van Der Mast. (2008). CoOccurrence of Depression and Anxiety in Elderly Subjects Aged 90 Years and Its Relationship with Functional Status, Quality of Life and Mortality International Journal of Geriatric Psychiatry DOI: 10.1002/Gps.2162. Retrieved from, www.Interscience.Wiley.Comon April, 5, 2013.

xxiii. 23. Morimoto SS, Kanellopoulos D, Manning KJ, Alexopoulos GS. Diagnosis and Treatment of Depression and Cognitive Impairment in Late-Life. Annals of the New York Academy of Sciences. 2015;1345(1):36-46. doi:10.1111/ nyas.12669.

xxiv. 24. Bierman, E, Comijs, H, and Jonker, (2009). The Effect of Anxiety and Depression on Decline Memory Function in Alzheimer's disease, International Psycho Geriatrics, 21, 1142-1147

xxv. 25. Chodosh, J., Kado, D.M., Seeman, T.E. and Arun, S. (2007). Depressive Symptoms as a Predictor of Cognitive Decline: Macarthur Studies of Successful Aging. American Journal of Geriatric Psychiatry, 15, 406-415.

xxvi. 26. Stillman, A.,Rowe K.,Arndt, S, and Moser, D. (2012). Anxious Symptoms and Cognitive Function in NonDemented Older Adults: An Inverse Relationship. Int J Geriatr Psychiatry. 27(8):792-8. Doi: 10.1002/ Gps.2785. Epub 2011 Sep 15. John Wiley \& Sons,Ltd. Retrieved from, http:/ / www.journals.cambridge.org/ ipgdoi:10.1017/S10416 on April,11,2013.

xxvii. 27. Kim, O., S., Yang, K., M., Kim, K., H. (2003). Dependency, Abuse, and Depression by Gender in Widowed Elderly. Taehan Kanho Hakhoe Chi; 35(2): 336-43.

xxviii. 28. Adam S, BonsangE, Germain S \& Perelman S (2007). Retirement and cognitive reserve: A stochastic frontier approach applied to survey data. Available at: http://www.crepp.ulg.ac.be/papers/crepp-wp200704.pdf [Accessed 4 Apr. 2018].

xxix. 29. Naveen KD \& Sudhakar TP (2013). Prevalence of cognitive impairment and depression among elderly patients attending the medicine outpatient of a tertiary care hospital in South India. International Journal of Research in Medical Sciences, 1(4), 359-364.

xxx. 30. Alley D, Suthers K \& Crimmins K (2007). Education and cognitive decline in older Americans. Research on Aging, 29 (1), 73 - 94.

xxxi. 31. De AzeredoPassos V, Giatti L, Bensenor I, Tiemeier H, Ikram M., de Figueiredo R, Chor D, Schmidt M \& Barreto $S$ (2015). Education plays a greater role than age in cognitive test performance among participants of the Brazilian Longitudinal Study of Adult Health (ELSA-Brasil). BMC Neurology, 15(1).

xxxii. 32. Lenehan ME, Summers MJ, Saunders NL, Summers JJ \& Vickers JC (2014). Relationship between education and age-related cognitive decline: A review of recent research. Psychogeriatrics 2015; 15: 154-162.

xxxiii. 33. Wilson RS, Hebert LE, Scherr PA, Barnes LL, Mendes de Leon CF\& Evans MD. (2009). Educational attainment and cognitive decline in old age. Neurology, 72(5), pp.460-465.

xxxiv. 34. Leibovici D, Ritchie K, Ledesert B, Touchon J (1992). Does education level determine the course of cognitive decline? Age and Ageing 1996:25:392-397.

xxxv. 35. Zhang Z. (2006). Gender Differentials in Cognitive Impairment and Decline of the Oldest Old in China. The Journals of Gerontology Series B: Psychological Sciences and Social Sciences, 61(2), pp. S107-S115.

xxxvi. 36. Rotar O, Moguchaya E, Alieva A, Orlov A, Boyarinova, M, VasilievaE, Solntsev V \&Konradi A (2015). Gender differences of the cognitive function in the elderly. Journal of Hypertension, 33, p.e440. doi: 10.1097/ 01.hjh.0000468763.05365.31. 